\title{
Cardiac Arrest due to Carbon Dioxide Embolism During Laparoscopic Gynecologic Surgery of a Patient with Previous Abdominal Surgery: A Case Report
}

\section{Nan Seol Kim}

Department of Anesthesiology and Pain Medicine, Soonchunhyang University Cheonan Hospital, Soonchunhyang University College of Medicine, Cheonan, Korea

\begin{abstract}
Catastrophic carbon dioxide $\left(\mathrm{CO}_{2}\right)$ embolism is a rare, but potentially life-threatening, the complication of laparoscopic gynecologic surgery. We report the case of a healthy 53-year-old woman who developed $\mathrm{CO}_{2}$ embolism and cardiac arrest during laparoscopic surgery. She had a history of two cesarean sections and had extensive peritoneal adhesions. After placement of the trocar and insufflation of $\mathrm{CO}_{2}$, end-tidal $\mathrm{CO}_{2}$ dropped from 35 to $15 \mathrm{~mm} \mathrm{Hg}$, and the patient had a cardiovascular collapse. In this patient, $\mathrm{CO}_{2}$ embolism was diagnosed on the basis of a sudden decrease in end-tidal $\mathrm{CO}_{2}$, hypotension, and hypoxemia. The patient was managed quickly and aggressively. The patient recovered completely following the treatment for $\mathrm{CO}_{2}$ embolism, with no cardiopulmonary or neurological sequelae. There is an increased risk of catastrophic $\mathrm{CO}_{2}$ embolism during laparoscopic gynecologic surgery in patients with previous abdominal surgery. Therefore, the surgeon and anesthesiologist should remain vigilant to promote early detection of $\mathrm{CO}_{2}$ embolism.
\end{abstract}

Keywords: Carbon dioxide; Embolism; Laparoscopy; Case report

\section{INTRODUCTION}

Laparoscopic surgery is widely accepted as an alternative to open surgery for the management of various benign gynecologic diseases. Compared to laparotomy, laparoscopy is associated with less pain and bleeding because of smaller incisions, as well as a shorter recovery time [1]. However, there are concerns about the potential serious complications of laparoscopy, including puncture of hollow viscera and major vessels, hemorrhage, subcutaneous emphysema, pneumomediastinum, pneumothorax, and gas embolism [2,3]. Gas embolism is a rare but life-threatening complication of laparoscopy, with a mortality rate of $28.5 \%$ [4].

Gas insufflation is usually used during laparoscopic surgery for accurate visualization and manipulation. Carbon dioxide $\left(\mathrm{CO}_{2}\right)$ is typically used to create a pneumoperitoneum. Intravascular injection of $\mathrm{CO}_{2}$ may result from needle or trocar placement into a vessel, or gas insufflation into an abdominal organ. This complica- tion usually develops during the induction of pneumoperitoneum, particularly in patients with previous abdominal surgery [3].

We report a case of cardiac arrest associated with $\mathrm{CO}_{2}$ embolism during laparoscopic gynecologic surgery, in a patient with a history of abdominal surgery.

\section{CASE REPORT}

A 53-year-old female patient was scheduled for laparoscopic supracervical hysterectomy because of menorrhagia. Her surgical history included two cesarean sections. The patient did not have any significant medical history or drug allergies, and her blood tests, electrocardiogram, and chest radiography were normal.

Propofol was used to induce anesthesia, and rocuronium was used to facilitate endotracheal intubation. The patient was mechanically ventilated, and anesthesia was maintained with desflurane mixed with 30\% air and oxygen. After general anesthesia had 
been induced, the patient was changed from the supine to lithotomy position. Due to extensive adhesions, the surgeon attempted trocar insertion twice. Pneumoperitoneum was achieved with $\mathrm{CO}_{2}$ gas insufflation, and the intraabdominal pressure was maintained at $12 \mathrm{~mm} \mathrm{Hg}$. Shortly thereafter, the end-tidal $\mathrm{CO}_{2}$ dropped from 35 to $15 \mathrm{~mm} \mathrm{Hg}$, the oxygen saturation decreased from $99 \%$ to $85 \%$, the heart rate decreased to 45 beats $/ \mathrm{min}$, and profound hypotension (blood pressure: 69/25 $\mathrm{mm} \mathrm{Hg}$ ) developed, followed by an unrecordable blood pressure. And a few second later, ventricular fibrillation developed. The surgeon was advised to stop the surgery, and $\mathrm{CO}_{2}$ insufflation was stopped. Simultaneously, the patient was ventilated with $100 \%$ oxygen and hydrated with fluids. External cardiac compression was begun, and $1 \mathrm{mg}$ of epinephrine was injected twice. In addition, electric cardioversion was performed. Five minutes after the initiation of external cardiac massage, spontaneous circulation returned. The right radial artery was cannulated, and a central venous catheter was inserted into the right internal jugular vein. Aspiration from this catheter did not obtain gas. Transesophageal echocardiography (TEE) did not find evidence of gas bubbles or interventricular septal shift toward the left ventricle. An arterial blood gas analysis shortly after the event revealed the arterial $\mathrm{pH} 7.162$ and partial pressure of carbon dioxide $\left(\mathrm{PCO}_{2}\right) 66.9 \mathrm{~mm} \mathrm{Hg}$, partial pressure of oxygen $\left(\mathrm{PO}_{2}\right)$ $176.2 \mathrm{~mm} \mathrm{Hg}, \mathrm{HCO}_{3} 23.4 \mathrm{mEq} / \mathrm{L}$, arterial oxygen saturation $\left(\mathrm{SaO}_{2}\right) 98.7 \%$, and fraction of inspired oxygen $\left(\mathrm{FiO}_{2}\right)$ was 1.0 , suggesting respiratory acidosis and decreased perfusion, consistent with $\mathrm{CO}_{2}$ embolism. Because of transient improvements with epinephrine boluses, norepinephrine and dopamine infusion was started. A repeat arterial blood gas analysis showed a $\mathrm{pH}$ of 7.264, $\mathrm{PCO}_{2}$ of $48.5 \mathrm{~mm} \mathrm{Hg}, \mathrm{PO}_{2}$ of $448.9 \mathrm{~mm} \mathrm{Hg}, \mathrm{HCO}_{3}$ of $21.5 \mathrm{mEq} / \mathrm{L}$, $\mathrm{SaO}_{2}$ of $98.7 \%$, and $\mathrm{FiO}_{2}$ of 1.0 . The patient recovered from the cardiac arrest, but remained hemodynamically unstable. Therefore, she was transferred to the intensive care unit (ICU) with continuous vasopressor infusion, and subsequently managed by the ICU physician.

The patient was extubated and the vasopressor infusion was discontinued on the first postoperative day. She was moved to the general ward on postoperative day 4 , and discharged on day 13 without any cardiopulmonary or neurological sequelae.

Written informed consent was obtained from the patients for the publication of this report. As this case was not a clinical trial, no ethical approval was required.

\section{DISCUSSION}

$\mathrm{CO}_{2}$ is an inexpensive gas that is more soluble in blood compared to air, oxygen, and $\mathrm{N}_{2} \mathrm{O} \cdot \mathrm{CO}_{2}$ is rapidly eliminated from the body and is non-combustible. Rapid elimination of $\mathrm{CO}_{2}$ increases the safety margin in cases of accidental intravenous injection [5]. The definitive diagnosis of $\mathrm{CO}_{2}$ embolism depends on the detection of $\mathrm{CO}_{2}$ emboli in the right side of the heart; however, due to the rapid elimination of $\mathrm{CO}_{2}$, other physiological parameters must be used for diagnosis [6].

$\mathrm{CO}_{2}$ embolism may be asymptomatic but can lead to neurologic injury, cardiovascular collapse, and even death. The presentation of $\mathrm{CO}_{2}$ embolism depends on the speed and volume of the embolized gas that enters the blood [7].

A previous study reported that adhesions, formed as a result of visceral or parietal peritoneum injury, were found in $94 \%$ of patients after laparotomy [8]. Therefore, patients with a history of abdominal surgery are at risk for adhesions [4]. In our patient, previous cesarean sections caused the severe intraabdominal adhesions, which may have been responsible for the accidental intravascular injection of $\mathrm{CO}_{2}$.

Embolism occurs when gas or other particulate matter enters the systemic venous system. End-tidal $\mathrm{CO}_{2}$ is the most important parameter for early detection of $\mathrm{CO}_{2}$ embolism. A rapid decrease in end-tidal $\mathrm{CO}_{2}$ may be caused by obstruction of the pulmonary vasculature by emboli, which expands the ventilatory dead space and is a reliable indicator of $\mathrm{CO}_{2}$ embolism [9]. However, other causes, such as air embolism and thromboembolism, should be excluded [5]. In our patient, $\mathrm{CO}_{2}$ embolism was diagnosed on the basis of a sudden decrease in end-tidal $\mathrm{CO}_{2}$, accompanied by hypotension and hypoxemia.

As mentioned previously, $\mathrm{CO}_{2}$ is more soluble in blood compared to air and nitrous oxide. Therefore, $\mathrm{CO}_{2}$ will not remain in the gas form for a long time. The lethal dose of air is approximately five times lower than that of $\mathrm{CO}_{2}$. Therefore, air embolism is far more dangerous than $\mathrm{CO}_{2}$ embolism [4]. In addition, $\mathrm{CO}_{2}$ embolism must be differentiated from thromboembolism, because the composition of embolic materials and treatment regimens differ.

TEE is the most sensitive technique to diagnose gas embolism. However, disadvantages of this technique include its high cost, technical complexity, invasive nature, and the need for an experienced anesthesiologist [10]. In addition, laparoscopic surgery is commonly performed even in hospitals without TEE, which is not 
routinely recommended during laparoscopy. Furthermore, $\mathrm{CO}_{2}$ embolism may be missed on TEE because of rapid elimination of $\mathrm{CO}_{2}$. Therefore, it may not be possible to detect gas bubbles unless TEE is prepared before insufflation, as in our case.

When a massive $\mathrm{CO}_{2}$ embolism is suspected, the anesthesiologist must advise the surgeons to terminate the surgery, and administer $100 \%$ oxygen to correct the hypoxemia and reduce the size of the embolus. Gas insufflation should be stopped, and the entrained gas should be eliminated if possible. The patient should be placed in the left lateral decubitus/steep head down (Durant) position. If these measures are not effective, a central venous catheter may be introduced to aspirate the gas. In our case, we attempted to aspirate the gas bubbles through the central venous catheter, but this failed. Norepinephrine significantly improves ventricular performance without constricting the pulmonary or renal circulation [9].

In previous report, surgery was safely performed after treatment for $\mathrm{CO}_{2}$ embolism [4]. However, our patient was hemodynamically unstable. Therefore, surgery was terminated and she was transferred to the ICU. Because there was no definitive evidence of $\mathrm{CO}_{2}$ embolism, the ICU physician managed the patient as in pulmonary thromboembolism, i.e., with heparin and tissue plasminogen activator. Pulmonary angiography was performed to exclude the possibility of pulmonary thromboembolism but there was no evidence of thromboembolism.

In conclusion, there is an increased risk of catastrophic $\mathrm{CO}_{2} \mathrm{em}-$ bolism during laparoscopic gynecologic surgery in patients with a history of abdominal surgery. Therefore, the surgeon and anesthesiologist should remain vigilant to promote early detection of $\mathrm{CO}_{2}$ embolism. In addition, communication with other healthcare personnel, including the ICU physicians, is essential for optimal management of these patients.

\section{CONFLICT OF INTEREST}

No potential conflict of interest relevant to this article was reported.

\section{REFERENCES}

1. Aarts JW, Nieboer TE, Johnson N, Tavender E, Garry R, Mol BW, et al. Surgical approach to hysterectomy for benign gynaecological disease. Cochrane Database Syst Rev 2015;2015:CD003677.

2. Lam A, Khong SY, Bignardi T. Principles and strategies for dealing with complications in laparoscopy. Curr Opin Obstet Gynecol 2010;22:315-9.

3. Magrina JF. Complications of laparoscopic surgery. Clin Obstet Gynecol 2002;45:469-80.

4. Cottin V, Delafosse B, Viale JP. Gas embolism during laparoscopy: a report of seven cases in patients with previous abdominal surgical history. Surg Endosc 1996;10:166-9.

5. Orhurhu VJ, Gao CC, Ku C. Carbon dioxide embolism. Treasure Island (FL): StatPearls Publishing; 2021.

6. Cadis AS, Velasquez CD, Brauer M, Hoak B. Intraoperative management of a carbon dioxide embolus in the setting of laparoscopic cholecystectomy for a patient with primary biliary cirrhosis: a case report. Int J Surg Case Rep 2014;5:833-5.

7. Li Y, Zhang E, Yuan H. Cerebral carbon dioxide embolism after kidney cancer laparoscopic surgery with full neurological recovery: a case report. Medicine (Baltimore) 2020;99:e20986.

8. Farag S, Padilla PF, Smith KA, Sprague ML, Zimberg SE. Management, prevention, and sequelae of adhesions in women undergoing laparoscopic gynecologic surgery: a systematic review. J Minim Invasive Gynecol 2018;25:1194-216.

9. Park EY, Kwon JY, Kim KJ. Carbon dioxide embolism during laparoscopic surgery. Yonsei Med J 2012;53:459-66.

10. Mann C, Boccara G, Fabre JM, Grevy V, Colson P. The detection of carbon dioxide embolism during laparoscopy in pigs: a comparison of transesophageal Doppler and end-tidal carbon dioxide monitoring. Acta Anaesthesiol Scand 1997;41:281-6. 